\title{
Chemical Oscillations and Spatial Structures in Polymerisation Reactions
}

\author{
Issa Katime $^{1 *}$, Juan A Pérez-Ortiz ${ }^{1}$ and Eduardo Mendizábal ${ }^{2}$ \\ ${ }^{1}$ Grupo de Nuevos Materiales, Departamento de Química Física, Facultad de Ciencia y Tecnología, Campus de Leioa, Spain \\ ${ }^{2}$ CUCEI, Universidad de Guadalajara, Jalisco, México
}

\begin{abstract}
This article discusses the possibility of coupling a polymerization reaction to an oscillatory kinetic model, complemented by diffusion which can lead to spatial structure. We used three well-known mathematical models of oscillators: a variant of the Rossler multivibrator, a model proposed by Edelstein, and the Oregon Oscillator. One or some of the terms in the equations of these models come from a polymerization reaction, while the other terms of these equations will come from collateral processes. So, almost any reaction could become oscillatory and/or with dissipative structure, adding the adequate collateral processes. The propagation stages are considered as invariants and initiation reactions of order $\alpha=0,1$, or 2 , and termination reactions of order $\beta=1$ or 2 are assumed. Except in the case $\alpha=1, \beta=2$, all six remaining reactions combinations $(\alpha, \beta)$ can be coupled to least one, and often to several of the models. The effects of destabilization a stable homogeneous steady state by the presence of diffusion is also discussed, which is always be possible.
\end{abstract}

Keywords: Reaction kinetics; Rossler multivibrador; Oregon oscillator; Oscillatory chemical reactions

\section{Introduction}

Theoretical and experimental studies of oscillating reactions have been studied at many laboratories and the interest of this type of phenomena has increased rapidly which led to the discovery of oscillations in biochemical and chemical systems [1]. Interestingly, in the early studies, thermodynamicists and applied mathematicians worked out models for such reactions and discussed the feasibility of oscillations in homogeneous chemical systems. Later a general criterion was available for the type of chemical reactions that could present undamped oscillations [1].

When the first discoveries in oscillatory chemical reactions [2] and spatial structures were found in chemical systems [3] (e.g., concentration waves), mathematical expressions to fit experimental results were looked for.

Adequate models for the chemical oscillations [4] are provided by non-linear ordinary differential equations when they are considered as precursors of the formal kinetic development. Partial differential equations [5] could explain the appearance of spatial rearrangements when they are applied to the reaction kinetics considering spatial diffusion. There are some kinetic reaction mechanisms, which are in general very complex that can be fit to mathematical models to predict the apparition of oscillations and/or spatial arrangements [6]. Recently, it has been suggested [7] that the mathematical equations of these models could be divided in two groups. Some of these equations will consider the main reactions (object to study), and the rest of them will take in account collateral processes. So, almost any reaction could become oscillatory and/or with dissipative structure by adding the adequate collateral processes. In this paper, examples of the application of this idea to polymerisation reactions, is shown.

\section{General Theory}

\section{Polymerisation processes and rate equations [7]}

Three steps are considered in the polymerisation reactions:

$$
\text { Initiation: } \quad \alpha X \stackrel{k_{i}}{\longrightarrow} R
$$

where reaction rate is of the form $\mathrm{R}_{\mathrm{i}} \sim \mathrm{X}^{a}$, and $\alpha$ can take the values 0,1 or 2

Propagation: $\mathrm{R}+\mathrm{X} \stackrel{\mathrm{k}_{\mathrm{p}}}{\longrightarrow} \mathrm{R}$

reaction rate is of the form $R_{p} \sim R X$

Termination: $\beta \mathrm{R} \stackrel{\mathrm{k}_{\mathrm{t}}}{\longrightarrow}$ products

In this case reaction rate is of the form $R_{t} \sim R^{\beta}$ and $\beta$ can take the values 1 or 2 .

By assuming the steady state for the propagators $R$, that is $R_{i}$ $=R_{t}=\nabla R_{t}$ it is obtained that $R \sim X^{\alpha / \beta}$; then the expression for the polymerisation rate $\dot{\mathrm{X}}_{\text {pol }}$ becomes:

$\dot{X}_{p o l}=-\alpha \cdot k_{i} \cdot X^{\alpha}-k_{g} \cdot X^{\frac{\alpha}{\beta}+1}$

where $\mathrm{k}_{\mathrm{g}}$ includes the constants $\mathrm{k}_{\mathrm{p}}$ and $\mathrm{k}_{\mathrm{t}}$.

The term X represents monomer concentration, and the propagation stages are considered as invariants and the different mechanisms of the polymerisations will be denoted using the symbols $[\alpha],[7,8]$, where the initiation reaction $(\alpha)$ can be of zero, first, 1 , or second order and the termination reaction $(\beta)$ can be of of first or second order.

\section{Analysis without diffusion}

Ordinary differential equations system $[4,9]$ in two variables, $\mathrm{X}$ and Y, will be considered

$$
\begin{aligned}
& \dot{\mathrm{X}}=\mathrm{M}(\mathrm{X}, \mathrm{Y}) \\
& \dot{\mathrm{Y}}=\mathrm{N}(\mathrm{X}, \mathrm{Y})
\end{aligned}
$$

*Corresponding author: Issa Katime, Grupo de Nuevos Materiales, Departamento de Química Física, Facultad de Ciencia y Tecnología, Campus de Leioa, Spain; E-mail: qfpkaami@lg.ehu.es

Received September 11, 2015; Accepted September 15, 2015; Published September 22, 2015

Citation: Katime I, Pérez-Ortiz JA, Mendizábal E (2015) Chemical Oscillations and Spatial Structures in Polymerisation Reactions. Chem Sci J 6: 108 doi:10.4172/2150-3494.1000108

Copyright: ( $) 2015$ Katime I, et al. This is an open-access article distributed under the terms of the Creative Commons Attribution License, which permits unrestricted use, distribution, and reproduction in any medium, provided the original author and source are credited. 
where the variable $\mathrm{Y}$ represents the concentration of a specie that appears in a collateral process. The steady states denoted by $\mathrm{SS}_{(\mathrm{i})}$, fulfill the equalities $\mathrm{X}=0, \dot{\mathrm{Y}}=0$, and the $\mathrm{X}$ and $\mathrm{Y}$ concentrations can be calculated by solving $\mathrm{M}\left(\mathrm{X}_{0} \mathrm{Y}_{0}\right)=0, \mathrm{~N}\left(\mathrm{X}_{0} \mathrm{Y}_{0}\right)=0$ equations. $\mathrm{A}$ linearized variational system $[10,11]$ is obtained when considering the perturbations defined as:

$$
\begin{aligned}
& x(t)=X-X_{0} \\
& y(t)=Y-Y_{0}
\end{aligned}
$$

the system is of the form

-

$$
\begin{aligned}
& x=c x+g y \\
& y=a x+b y
\end{aligned}
$$

where the coefficients

$$
\mathrm{c}=\left(\frac{\partial \mathrm{M}}{\partial \mathrm{x}}\right)_{0}, \mathrm{~g}=\left(\frac{\partial \mathrm{M}}{\partial \mathrm{y}}\right)_{0}, \mathrm{a}=\left(\frac{\partial \mathrm{N}}{\partial \mathrm{x}}\right)_{0}, \mathrm{~b}=\left(\frac{\partial \mathrm{N}}{\partial \mathrm{y}}\right)_{0}
$$

are the elements of the characteristic no-diffusive matrix

$\mathrm{M}_{0}=\left(\begin{array}{ll}\mathrm{c} & \mathrm{g} \\ \mathrm{a} & \mathrm{b}\end{array}\right)$

This matrix trace is

$\mathrm{T}_{0}=\mathrm{b}+\mathrm{c}$

and its determinant is

Det $_{0}=\mathrm{bc}-\mathrm{a}$

In the neighbourhood of the steady state (SS) the solutions of (3) are in the form

$$
\begin{aligned}
& x=A e^{\omega t} \\
& y=B e^{\omega t}
\end{aligned}
$$

where, $\omega$ are the roots of the equation:

$$
\omega^{2}-\mathrm{T}_{0} \cdot \omega+\text { Det }_{0}=0
$$

The steady state is unstable if, at least, one of these roots has a positive real part. It occurs when Det $_{0}<0$. However, this condition causes the SS to be a "saddle point", which normally involves explosions, and so, it is discarded as realistic chemical model.

A root with a positive real part can be obtained if $\mathrm{T}_{0}>0$.

If $\mathrm{T}_{0}=0$ and the discriminant is:

$\Delta_{0}=\mathrm{T}_{0}^{2}-4$ Det $_{0}$

if Det $_{0}<0$ then $\Delta_{0}>0$, the steady state is a node; if $\operatorname{Det}_{0}>0$ then $\Delta_{0}$ $<0, \mathrm{i}$ the steady state $\mathrm{s}$ a focus.

In all the equations systems that will be examined, the condition Det $_{0}>0$ will be fulfilled, and the transitions from $\mathrm{T}_{0}<0$ to $\mathrm{T}_{0}=0$ and to $\mathrm{T}_{0}>0$ will be possible, that is, from a stable focus $\left(\mathrm{T}_{0} \leq 0, \Delta_{0} \approx-4\right.$ Det $_{0}<$ $0)$ to node $\left(\mathrm{T}_{0}=0, \Delta_{0}=-4 \operatorname{Det}_{0}<0\right)$ and to unstable focus $\left(\mathrm{T}_{0} \geq 0\right.$, $\Delta_{0} \approx-4$ Det $_{0}<0$ ). Hopf [12] proved that this bifurcation leads to the apparition of a limit cycle around the unstable focus, with sustained oscillations of the system. In this paper, the Hopf bifurcations existence in all the studied cases is verified.

\section{Including the diffusion process}

If diffusion effects along one dimension ( $r$ ) are considered, the equations (2) take the form $[13,10]$

$$
\begin{aligned}
& \frac{\partial \mathrm{X}}{\partial \mathrm{t}}=\mathrm{M}(\mathrm{X}, \mathrm{Y})+\mathrm{D}_{\mathrm{x}} \frac{\partial^{2} \mathrm{X}}{\partial \mathrm{r}^{2}} \\
& \frac{\partial \mathrm{Y}}{\partial \mathrm{t}}=\mathrm{N}(\mathrm{X}, \mathrm{Y})+\mathrm{D}_{\mathrm{y}} \frac{\partial^{2} \mathrm{Y}}{\partial \mathrm{r}^{2}}
\end{aligned}
$$

where $\mathrm{D}_{\mathrm{x}}$ and $\mathrm{D}_{\mathrm{y}}$ are diffusion coefficients, respectively. In this context, the steady states are named homogeneous steady state (HSS). Their stability can also be studied by linearization, and when suitable perturbations for the desired boundary conditions are defined. In this paper, the Neuman's conditions [10] (of no-flow in the system boundary) are used:

$$
\begin{aligned}
& \mathrm{x}(\mathrm{t}, \mathrm{r})=\mathrm{Ae}^{\omega \mathrm{t}} \cos n r=X-X_{0} \\
& \mathrm{y}(\mathrm{t}, \mathrm{r})=\mathrm{Be}^{\omega \mathrm{t}} \cos n r=Y-Y_{0}
\end{aligned}
$$

where $\mathrm{n}$ is the wave number, which under the conditions $\mathrm{x}(0, \mathrm{~L})$ $= \pm \mathrm{A}$ and $\mathrm{y}(0, \mathrm{~L})= \pm \mathrm{B}$, must satisfy,

$n=\frac{m \pi}{L}$

where $L$ is the length of the system and $m=0,1,2,3, \ldots$. (an integer)

The secular matrix of the linearized system takes the form

$$
M_{n}=\left(\begin{array}{ll}
c-D_{x} n^{2} & g \\
a & b-D_{y} n^{2}
\end{array}\right)
$$

whose trace is

$$
\mathrm{T}_{\mathrm{n}}=\mathrm{T}_{0}-\left(\mathrm{D}_{\mathrm{x}}+\mathrm{D}_{\mathrm{y}}\right) \cdot \mathrm{n}^{2}
$$

and the determinant is

$$
\operatorname{Det}_{\mathrm{n}}=\operatorname{Det}_{0}-\mathrm{n}^{2} \cdot\left(\mathrm{bD}_{\mathrm{x}}+\mathrm{cD}_{\mathrm{y}}\right)+\mathrm{D}_{\mathrm{x}} \cdot \mathrm{D}_{\mathrm{y}} \cdot \mathrm{n}^{4}
$$

Now, trace and determinant depend on the wave number, $n$. The roots of the secular equation

$$
\omega^{2}-\mathrm{T}_{\mathrm{n}} \cdot \omega+\operatorname{Det}_{\mathrm{n}}=0
$$

will be also dependent on the wave number. As in the no diffusive case, if one of those roots has a positive real part, the homogeneous steady state will be unstable. That can be so because of the conditions Det $_{n}<0$, or $T_{n}>0$. The condition $T_{n}>0$ is impossible to be fulfilled, unless in the no diffusive case $\mathrm{T}_{0}>0$, that is, the homogeneous steady state was already unstable in diffusion absence. So, it is impossible a homogeneous stable steady state, which fulfilled $\mathrm{T}_{0}<0$, Det ${ }_{0}>0$, to be destabilized by diffusion. Besides, in the case $\mathrm{T}_{0}>0$, if $\omega$ had a positive real part because of being $T_{n}>0$, that positive real part would be $\omega_{\text {Re+ }}=T_{n} / 2$ if $\Delta \mathrm{n}=\mathrm{T}_{\mathrm{n}}^{2}-4 \operatorname{Det}_{\mathrm{n}}<0$, or $\omega_{\text {Re+ }}=\left[\left(\mathrm{T}_{\mathrm{n}}+\Delta \mathrm{n}^{1 / 2}\right) / 2\right]$ if $\Delta \mathrm{n} \geq$ 0 ; in one or the other case, the higher positive value of this real part will be reached when $\mathrm{n}=0$. That means that in the case of where are several solutions (for some $\mathrm{n}$ values), when it is allowed by the limit conditions, the homogeneous solution $(\mathrm{n}=0)$, will be amplified faster and predominates above the no homogeneous ones, and the presence of spatial structures is not probable.

The condition Det $_{n}<0$ has not been considered yet. If $\mathrm{p}=\mathrm{n}^{2}$, it can be expressed as a second grade polynomial:

$$
\text { Det }_{\mathrm{n}}=\text { Det }_{0}-\mathrm{p} \cdot\left(\mathrm{bD}_{\mathrm{x}}+\mathrm{cD}_{\mathrm{y}}\right)+\mathrm{D}_{\mathrm{x}} \mathrm{D}_{\mathrm{y}} \mathrm{p}^{2}<0
$$

and it is possible that it could be fulfilled in some interval $p_{1}$ $<\mathrm{p}<\mathrm{p}_{2}$ (although $\mathrm{T}_{0}>0$ and Det $_{0}>0$, case in which it can be said that the homogeneous steady state can be destabilized by diffusion. Independently of $p_{2}>p_{1}>0$, and $p_{1} p_{2}=\operatorname{Det}_{0} / D \cdot D_{y}$, it is necessary Det $>0$ to be firstly fulfilled. Moreover, as $p_{1+} p_{2}=\left[\left(b \cdot D_{x}+c \cdot D_{y}\right) / D_{x} \cdot D_{y}\right]>0$, it is necessary that $\mathrm{bD}_{\mathrm{x}}+\mathrm{cD}_{\mathrm{y}}>0$. Finally, the condition for that interval 
to exist is that the discriminant must be positive,

$$
\Delta_{(16)}=\left(\mathrm{b} \cdot \mathrm{D}_{\mathrm{x}}+\mathrm{c} \cdot \mathrm{D}_{\mathrm{y}}\right)^{2}-4 \mathrm{D}_{\mathrm{x}} \cdot \mathrm{D}_{\mathrm{y}} \cdot \operatorname{Det}_{0}>0
$$

If all of those conditions are fulfilled, as $\mathrm{T}_{\mathrm{n}}<\mathrm{T}_{0}<0$, Det $_{\mathrm{n}}<0<$ Det $_{0}$, the inequality $\sqrt{\Delta_{\mathrm{n}}}>\sqrt{\Delta_{0}}$ will be also fulfilled, and so, $\mathrm{T}_{\mathrm{n}}+\sqrt{\Delta_{\mathrm{n}}}>\mathrm{T}_{0}+\sqrt{\Delta_{0}}$ could be accepted. The positive real part of $\omega$ will be higher for some $n$ $\neq 0$, than for $\mathrm{n}=0$, and if that is so, the no homogeneous perturbation increases more quickly than the homogeneous one (if both of them coexist and compete).

If the homogeneous steady state is unstabilized for any wave number, $\mathrm{n}$, an initial fluctuation having a Fourier component with that $\mathrm{n}$, will force the system to go out from the homogeneous steady state and a new spatial arrangement produced by fluctuations [14] will be obtained.

Now, the three mathematical models will be analysed.

\section{Models}

\section{Rossler modified model $[7,15,16]$}

1A. without diffusion:

$$
\left\{\begin{array}{l}
A_{1} \stackrel{m_{1}}{\longrightarrow} Y \stackrel{F}{\longrightarrow} \\
A_{2}+X \rightarrow 2 X \\
X+Y \stackrel{m_{2}}{\longrightarrow} Y+\text { degradation products of } X \\
2 X \stackrel{m_{3} \longrightarrow D_{1}}{\longrightarrow} 3 X \\
A_{3}+D_{1} \stackrel{m_{4}}{\longrightarrow} 3 X \underset{m_{5}}{\longrightarrow} D_{2} \\
2 X \stackrel{m_{7}}{\longrightarrow} D_{2}+\text { degradation products of } X \\
D_{2}+X \stackrel{k_{i}}{\longrightarrow} R \\
{\left[\begin{array}{l}
\alpha X \stackrel{k_{p}}{\longrightarrow} R \\
R+X \stackrel{k_{t}}{\longrightarrow} \text { polymer }
\end{array}\right]}
\end{array}\right.
$$

The kinetic equations:

$$
\left\{\begin{array}{l}
\dot{\mathrm{X}}=A_{1}-m_{1} X+A_{2} X-m_{2} X Y-2 m_{3} X^{2}+3 m_{1} A_{3} D_{1}-2 m_{5} X^{2}+2 m_{6} X^{2}-m_{7} D^{2} X-\alpha k_{i} X^{\alpha}-k_{p} R X \\
\dot{\mathrm{Y}}=m_{1} X-F Y \\
\dot{\mathrm{D}_{1}}=m_{3} X^{2}-m_{4} A_{3} D_{1} \\
\dot{\mathrm{D}_{2}}=m_{5} X^{2}-m_{6} D_{2} \\
\dot{\mathrm{R}}=k_{i} X^{\alpha}-\beta k_{t} R^{\beta}
\end{array}\right.
$$

When $\dot{\mathrm{D}}_{1}=0, \dot{\mathrm{D}}_{2}=0, \dot{\mathrm{R}}_{0}=0$, they are reduced to two equations: $\left\{\begin{array}{l}\dot{\mathrm{X}}=A_{1}+\left(A_{2}-m_{1}\right) X-m_{2} X Y+m_{3} X^{2}-\frac{m_{7} m_{5}}{m_{6}} X^{3}-\alpha k_{i} X^{\alpha}-k_{p}\left(\frac{k_{i}}{\beta k_{t}}\right)^{1 / \beta} X^{(\alpha / \beta)+1} \\ \dot{\mathrm{Y}}=m_{1} X-F Y\end{array}\right.$

and the following equations are obtained:

$$
\begin{aligned}
& \dot{X}=-k_{1} X Y+k_{2} X^{2}-k_{3} X^{3}+k_{4} X+k_{5} \\
& \dot{Y}=k_{6} X-k_{7} Y
\end{aligned}
$$

where the values of $\mathrm{k}_{1} \mathrm{k}_{2}, \mathrm{k}_{3}, \mathrm{k}_{4}, \mathrm{k}_{5}, \mathrm{k}_{6}$ and $\mathrm{k}_{7}$ are defined as follows: Considering the polymerizations types $\{0,1\}$ and $\{0,2\}$ :

$$
A_{1}=k_{5} ; A_{2}=m_{1}-k_{g}=k_{4}\left(\operatorname{con} k_{g}=k_{p}\left(\frac{k_{i}}{\beta k_{t}}\right)^{1 / \beta}, \beta=1, \beta=2\right) \text {, }
$$

$m_{2}=k_{1}, m_{3}=k_{2}, \underline{\mathrm{m}_{7} \mathrm{~m}_{5}}={ }_{3}, \mathrm{k}_{6}=\mathrm{m}_{1}, \mathrm{k}_{7}=-\mathrm{F}$

for the polymerization type $\{1,1\}$ :

$A_{1}=k_{5} ; A_{2}=-m_{1}-k_{i}=k_{4}, m_{2}=k_{1}, m_{3}-\frac{k_{i} k_{p}}{\beta k_{t}}=k_{2}, \frac{m_{7} m_{5}}{m_{6}}=k_{3}, m_{1}=k_{6}, F=k_{7}$ for polymerization type $\{2,1\}$ :

$A_{1}=k_{5} ; A_{2}-m_{1}=k_{4}, m_{2}=k_{1}, m_{3}-2 k_{i}=k_{2}, \frac{m_{7} m_{5}}{m_{6}}+k_{p}\left(\frac{k_{i}}{2 k_{t}}\right)^{1 / 2}=k_{3}, m_{1}=k_{6}, F=k_{7}$ when the polymerization type $\{2,2\}$ is considered:

$A_{1}=k_{5} ; A_{2}-m_{1}=k_{4}, m_{2}=k_{1}, m_{3}-2 k_{i}-k_{p}\left(\frac{k_{i}}{2 k_{t}}\right)=k_{2}, \frac{m_{7} m_{5}}{m_{6}}=k_{3}, m_{1}=k_{6}, F=k_{7}$

A. A concrete case [7] will be considered. With the following values of the constants: $\mathrm{k}_{1}=1, \mathrm{k}_{2}=0.9, \mathrm{k}_{3}=1, \mathrm{k}_{4}=0.2, \mathrm{k}_{5}=0.01, \mathrm{k}_{6}=1.5 \varepsilon$ and $\mathrm{k}_{7}=\varepsilon$. The system becomes :

$$
\begin{aligned}
& \dot{X}=-X Y+0.9 X^{2}-X^{3}+0.2 X+0.01 \\
& \dot{Y}=\varepsilon(1.5 X-Y)
\end{aligned}
$$

This system has an only one homogeneous steady state $\left(\mathrm{X}_{0}=0.271\right.$, $\left.\mathrm{Y}_{0}=0.4065\right)$ and its secular matrix is

$$
\mathrm{M}_{0}=\left(\begin{array}{ll}
\mathrm{c}=0.061 & \mathrm{~g}=-0.7305 \\
\mathrm{a}=1.5 \varepsilon & \mathrm{b}=-\varepsilon
\end{array}\right)
$$

with $\mathrm{T}_{0}=0.061-\varepsilon$, will be positive if $\varepsilon<0.061$, and Det ${ }_{0}=0.3455 \varepsilon$ $>0$. So, (19) admits Hopf bifurcation and a limit cycle around the unstable steady state for $\varepsilon<0.061$.

1B. Considering that there is a diffusion process, (18) becomes:

$$
\begin{aligned}
& \frac{\partial X}{\partial t}=-k_{1} X Y+k_{2} X_{2}-k_{3} X_{3}+k_{4} X+k_{5}+D_{x} \frac{\partial^{2} X}{\partial r^{2}} \\
& \frac{\partial Y}{\partial t}=k_{6} X-k_{7} Y+D_{y} \frac{\partial^{2} Y}{\partial r^{2}}
\end{aligned}
$$

and using the constants values of Section $1 \mathrm{~A}$

$$
\begin{aligned}
& \frac{\partial X}{\partial t}=-X Y+0.9 X_{2}-X_{3}+0.2 X+0.01+D_{x} \frac{\partial^{2} X}{\partial r^{2}} \\
& \frac{\partial Y}{\partial t}=\varepsilon \cdot(1.5 X-Y)+D_{y} \frac{\partial^{2} Y}{\partial r^{2}}
\end{aligned}
$$

The secular matrix is

$$
\mathrm{M}_{\mathrm{n}}=\left(\begin{array}{lc}
0.061-\mathrm{D}_{\mathrm{x}} \mathrm{n}^{2} & -0.271 \\
1.5 \varepsilon & -\varepsilon-\mathrm{D}_{\mathrm{y}} \mathrm{n}^{2}
\end{array}\right)
$$

whose trace is $T_{n}=0,061-\varepsilon-\left(D_{x}+D_{y}\right) n^{2}$, and the determinant, Det $=0.3455 \varepsilon-\mathrm{n}^{2} \cdot\left(0.061 \cdot \mathrm{D}_{y}-\varepsilon \cdot \mathrm{D}_{\mathrm{x}}\right)+\mathrm{D}_{\mathrm{x}} \mathrm{D}_{\mathrm{y}} \mathrm{n}^{4}$. The condition Det $>0$ is fulfilled; the $\mathrm{bD}_{\mathrm{x}}+\mathrm{cD}_{\mathrm{y}}>0$ implies that $0.061 \mathrm{D}_{\mathrm{y}}>\varepsilon \cdot \mathrm{D}_{\mathrm{x}}$, and (17) requires $\left(0.061 \mathrm{D}_{\mathrm{y}}-\varepsilon \mathrm{D}_{\mathrm{x}}\right)^{2}>4 \mathrm{D}_{\mathrm{x}} \cdot \mathrm{Dy} \cdot 0.3455 \varepsilon$. For $\varepsilon=1$ (value in which $\left.\mathrm{T}_{0}<0\right), \mathrm{D}_{\mathrm{x}}$ $=1, D_{y}=600$ (adequate units), this condition is also fulfilled. $p=0.025$

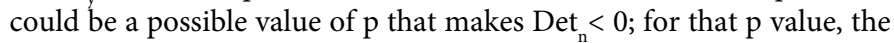
real part of $\mathrm{T}_{0}$ is $(0.021 / 2)$, and its higher than the real part of $\mathrm{T}_{0}$, $\left(\mathrm{T}_{0} / 2\right)<0$ (since $\Delta_{0} \approx-0.5<0$, the homogeneous steady state was an stable state).

\section{Edelstein model $[7,17,18]$}

2A. This model is based in an enzymatic mechanism [18-20] whose substrate is monomer $\mathrm{X}$. That makes possible to be applied in biochemical polymerisations 


$$
\left\{\begin{array}{l}
A_{1} \rightarrow U \\
A x+U \stackrel{m_{1}}{\longrightarrow} 2 X \\
X+X \stackrel{m_{2}}{\rightleftarrows} C \\
C \stackrel{m_{3}}{\stackrel{m_{4}}{\rightleftarrows}} Z+P \\
{\left[\begin{array}{l}
2 X \stackrel{m_{5}}{\longrightarrow} \mathrm{R} \\
R+X \stackrel{k_{p}}{\longrightarrow} R \\
2 R \stackrel{k_{t}}{\longrightarrow} \text { polymer }
\end{array}\right]}
\end{array}\right.
$$

The kinetic equations are:

$$
\left\{\begin{array}{l}
\dot{X}=m_{1} X U-2 m_{2} X Y+m_{3} C+m_{4} C-k_{p} R X \\
\dot{U}=A_{2}-m_{2} X U \\
\dot{Z}=-m_{2} Z X+m_{3} C+m_{4} C-m_{5} Z Y \\
\dot{C}=m_{2} Z X-m_{3} C-m_{4} C+m_{5} Z p \\
\dot{R}=k_{i} X^{2}-2 k_{t} R^{2}
\end{array}\right.
$$

Which are reduced to two variables if $\dot{Z}=0, \dot{\mathrm{R}}=0, \dot{C}=0$. Observe that $\dot{Z}+\dot{C}=0$, then $\mathrm{Z}+\mathrm{C}=\mathrm{B}=$ constant, resulting in the following equations:

$\left\{\begin{array}{l}\dot{\mathrm{X}}=m_{1} X U-\left(2 k_{i}+k_{p} \cdot \sqrt{a^{2}+k_{i} / 2 k_{t}}\right) X^{2}-\left[B\left(m_{3}+m_{4}\right)\left(m_{1} X+m_{3}\right) /\left(m_{2} X+m_{5} p+m_{3}+m_{4}\right)\right] \\ \dot{\mathrm{Y}}=A_{1}-m_{1} X U\end{array}\right.$

with the definitions

$\mathrm{A}_{1}=\mathrm{A}_{2} / \mu, \mathrm{m}_{2} / \mu=\mathrm{k}_{\mathrm{i}}, 2 \mathrm{k}_{1}+\mathrm{k}_{\mathrm{p}} \sqrt{\mathrm{k}_{\mathrm{i}} / 2 \mathrm{k}_{\mathrm{t}}}=\mathrm{k}_{2}, B\left(\mathrm{~m}_{3}+m_{4}\right) m_{2}=\mathrm{k}_{3}, B\left(\mathrm{~m}_{3}+m_{4}\right) m_{3}=\mathrm{k}_{4}, \mathrm{~m}_{3} B=\mathrm{k}_{5}, A_{2}=k_{8}, m_{1}=k_{9}$

it is obtained:

$$
\begin{aligned}
& \dot{X}=k_{1} X Y-k_{2} X^{2}-\frac{k_{3} X+k_{4}}{k_{5} X+k_{6}}+k_{7} \\
& \dot{Y}=k_{8}-k_{9} X Y
\end{aligned}
$$

This model applies only to the polymerization type $\{2,2\}$.

Considering the following values [7] for the constants (in adequate units): $\mathrm{k}_{1}=1 / \mu, \mathrm{k}_{2}=1 / \mu, \mathrm{k}_{3}=60 / \mu, \mathrm{k}_{4}=60 / \mu, \mathrm{k}_{5}=1, \mathrm{k}_{6}=2.2, \mathrm{k}_{7}=30 / \mu, \mathrm{k}_{8}$ $=16.858$ and $\mathrm{k}_{9}=1$, the equations system becomes:

$$
\begin{aligned}
& \dot{X}=\frac{1}{\mu}\left(X Y-X^{2}-\frac{60(X+1)}{X+2.2}+30\right) \\
& \dot{Y}=16.858-X Y
\end{aligned}
$$

which has a steady state in $\mathrm{X}_{0}=2, \mathrm{Y}_{0}=8.429$. The secular matrix is

$$
M_{n}=\left(\begin{array}{cc}
c=\frac{0.3474}{\mu} & \mathrm{g}=\frac{2}{\mu} \\
\mathrm{a}=-8.429 & \mathrm{~b}=-2
\end{array}\right)
$$

and the trace, $T_{0}=(0.3474 / \mu)-2$, if $\mathrm{T}_{0}=0.1737$, then $\mathrm{T}_{0}>0$. Moreover, Det $_{0}=\left(16.1633 / \mathrm{T}_{0}\right)>0$. So, if $\mu<0.1737$, a limit cycle around the unstable steady state exits.

2B. If the diffusion is considered, (30) can be written as

$$
\begin{aligned}
& \frac{\partial X}{\partial t}=k_{1} X Y-k_{2} X^{2}-\frac{k_{3} X+k_{4}}{k_{5} X+k_{6}}+k_{7}+D_{x} \frac{\partial^{2} X}{\partial r^{2}} \\
& \frac{\partial Y}{\partial t}=k_{8}-k_{9} X Y+D_{y} \frac{\partial^{2} Y}{\partial r^{2}}
\end{aligned}
$$

and with the values for the parameters previously used:

$$
\begin{aligned}
& \frac{\partial X}{\partial t}=\frac{1}{\mu}\left(X Y-X^{2}-\frac{60(X+1)}{X+2,2}+30\right)+D_{x} \frac{\partial^{2} X}{\partial r^{2}} \\
& \frac{\partial Y}{\partial t}=16,858-X Y+D_{y} \frac{\partial^{2} Y}{\partial r^{2}}
\end{aligned}
$$

The secular matrix is

$$
\mathrm{M}_{\mathrm{n}}=\left(\begin{array}{ll}
\frac{0.3474}{\mu}-\mathrm{D}_{\mathrm{x}} \mathrm{n}^{2} & \frac{2}{\mu} \\
-8.429 & -2-\mathrm{D}_{\mathrm{y}} \mathrm{n}^{2}
\end{array}\right)
$$

whose trace is

$$
\mathrm{T}_{\mathrm{n}}=\frac{0.3474}{\mu}-2-\left(\mathrm{D}_{\mathrm{x}}+\mathrm{D}_{\mathrm{y}}\right) \mathrm{n}^{2}
$$

and the determinant

$$
\operatorname{Det}_{n}=\frac{16.1633}{\mu}-n^{2}\left(\frac{0.3474}{\mu} D_{y}-2 D_{x}\right)+D_{x} D_{y} n^{4}
$$

Det $_{0}>0$ is fulfilled. In order to fulfill the conditions

$$
\begin{aligned}
& \frac{0.3474}{\mu} D_{\mathrm{y}}>2 \mathrm{D}_{\mathrm{x}} \\
& \text { and } \\
& \left(\frac{0.3474}{\mu} D_{y}-2 D_{x}\right)^{2}>4 D_{y} D_{x} \frac{16.1633}{\mu}
\end{aligned}
$$

the values $\mu=1$ (that leads to $T_{0}<0$ ), $D_{x}=1, D_{y}=600$, are used. So, the conditions for Det ${ }_{n}<0$ are fulfilled if $p=0.2$, value that provides a real part of $\omega(0.0181 / 2)$, higher than the real part of $\omega_{0}$ (without diffusion), $\left(\omega_{0} / 2\right)<0$, since $\Delta_{0}<0$. The homogeneous steady state was a stable focus and it could be destabilized by diffusion.

\section{Oregon oscillator [7,21], Stiffly coupled oregonator [22]}

5A. It was conceived first by Field and Noyes [21] as a model developed from the well-known Belousov-Zhabotinsky oscillating reaction [2]. Those authors explained it in three variables, but it is possible to reduce it to two variables assuming that the third one is always maintained in steady state (stiff coupling) [23], without losing its main important characteristics.

$$
\left\{\begin{array}{l}
A_{1}+Z \rightarrow X \\
Z+X \stackrel{m_{1}}{\longrightarrow} \text { destruction products of } \mathrm{Z} \\
A_{2}+X \rightarrow 2 X+Y \\
2 X \stackrel{m_{2}}{\longrightarrow} \text { inactive dimer, } \mathrm{D}_{1} \\
\mathrm{Y} \stackrel{m_{3}}{\longrightarrow} Z \\
{\left[\begin{array}{l}
\alpha X \stackrel{k_{i}}{\longrightarrow} \mathrm{R} \\
R+X \stackrel{k_{p}}{\longrightarrow} R \\
\beta R \stackrel{k_{t}}{\longrightarrow} \text { polymer }
\end{array}\right]}
\end{array}\right.
$$

The kinetic equations are: 


$$
\left\{\begin{array}{l}
\dot{\mathrm{X}}=A_{1} Z-2 m_{1} Z X+A_{2} X-2 m_{2} X^{2}-\alpha k_{i} X^{\alpha}-k_{p} R X \\
\dot{Y}=A_{2} X-m_{3} Y \\
\dot{Z}=-A_{1} Z-m_{3} Y \\
\dot{R}=k_{i} X^{\alpha}-\beta k_{t} R^{\beta}
\end{array}\right.
$$

Which are reduced to two variables if $\dot{Z}=0$ (stiff coupling), $\dot{R}=0$;

$$
\left\{\begin{array}{l}
\dot{\mathrm{X}}=\frac{\left(A_{1}-m_{1} X\right) m_{3} Y}{A_{1}+m_{1} X}+A_{2} X-2 m_{2} X^{2}-\alpha k_{i} X^{\alpha}-k_{p}\left(\frac{k_{i}}{\beta k_{t}}\right)^{1 / \beta} X^{(\alpha / \beta)+1} \\
\dot{\mathrm{Y}}=A_{2} X-m_{3} Y
\end{array}\right.
$$

Considering polymerizations type $\{0,1\}$ and $\{0,2\}$ and with the definitions:

$$
\mathrm{A}_{1}=\mathrm{k}_{1}, \mathrm{~m}_{1}=\mathrm{k}_{2}, \mathrm{~A}_{1} / \mathrm{m}_{3}=\mathrm{k}_{3}, \mathrm{~m}_{1} / \mathrm{m}_{3}=\mathrm{k}_{4}, \mathrm{k}_{6}=2 \mathrm{~m}_{2}+, \mathrm{k}_{5}=\mathrm{A}_{2}-\mathrm{k}_{\mathrm{p}}\left(\mathrm{k}_{\mathrm{i}} / \beta \mathrm{k}_{\mathrm{t}}\right)^{1 / \beta}, \mathrm{k}_{7}=\mathrm{A}_{2}, \mathrm{k}_{8}=\mathrm{m}_{3}
$$

The kinetic equations take the form:

$$
\begin{aligned}
& \dot{X}=\frac{Y\left(k_{1}-k_{2} X\right)}{k_{3}+k_{4} X}+k_{5} X-k_{6} X^{2} \\
& \dot{Y}=k_{7} X-k_{8} Y
\end{aligned}
$$

Polymerization type $\{1,1\}$ with the definitions:

$\mathrm{A}_{1}=\mathrm{k}_{1}, \mathrm{~m}_{1}=\mathrm{k}_{2}, \mathrm{~A}_{1} / \mathrm{m}_{3}=\mathrm{k}_{3}, \mathrm{~m}_{1} / \mathrm{m}_{3}=\mathrm{k}_{4}, \mathrm{k}_{5}=\mathrm{A}_{2}-\mathrm{k}_{i}, \mathrm{k}_{6}=2 \mathrm{~m}_{2}+\mathrm{k}_{\mathrm{p}}\left(\mathrm{k}_{\mathrm{i}} / \mathrm{k}_{\mathrm{t}}\right), \mathrm{k}_{7}=\mathrm{A}_{2}, \mathrm{k}_{8}=\mathrm{m}_{3}$

results in (34).

$\mathrm{A}_{1}=\mathrm{k}_{1}, \mathrm{~m}_{1}=\mathrm{k}_{2}, \mathrm{~A}_{2} / \mathrm{m}_{3}=\mathrm{k}_{3}, \mathrm{~m}_{1} / \mathrm{m}_{3}=\mathrm{k}_{4}, \mathrm{k}_{5}=\mathrm{A}_{2}, k_{6}=2 m_{2}+2 k_{i}+k_{p}\left(k_{i} / 2 k_{t}\right)^{1 / 2}$,

$k_{7}=A_{2}, k_{8}=m_{3}$

Polymerization $\{2,2\}$ and the definitions:

give as a result equations (34)

3A. Assuming the following values for the parameters [7] $\mathrm{k}_{1}=1$, $\mathrm{k}_{2}=1, \mathrm{k}_{3}=1, \mathrm{k}_{4}=1, \mathrm{k}_{5}=1$ and $\mathrm{k}_{6}=8.375 \cdot 10^{-6}$ (proposed value by Field y Noyes considering the bromine chemistry [24], in order to explain the Belousov-Zhabotinsky reaction); $\mathrm{k}_{7}=\varepsilon$ and $\mathrm{k}_{8}=\varepsilon$, the system (34) becomes:

$$
\begin{aligned}
& \dot{X}=\frac{Y(1-X)}{1+X}+X-8.375 \cdot 10^{-6} X^{2} \\
& \dot{Y}=\varepsilon(X-Y)
\end{aligned}
$$

There is a steady state in $\mathrm{X}_{0}=\mathrm{Y}_{0}=488.68$. The secular matrix is

$$
\mathrm{M}_{0}=\left(\begin{array}{cc}
\mathrm{c}=0.9877 & \mathrm{~g}=-0.9959 \\
\mathrm{a}=\varepsilon & \mathrm{b}=-\varepsilon
\end{array}\right)
$$

and the trace is $\mathrm{T}_{0}=0.9877-\varepsilon$. Det $_{0}=8.176 \cdot 10^{-3} \varepsilon>0$. If $\varepsilon<0.9877$, the steady state will be unstable and a limit cycle around it will be arise.

3B. Introducing the diffusion process, (34) can be written as

$$
\begin{aligned}
& \frac{\partial \mathrm{X}}{\partial \mathrm{t}}=\frac{\mathrm{Y}\left(\mathrm{k}_{1}-\mathrm{k}_{2} \mathrm{X}\right)}{\mathrm{k}_{3}+\mathrm{k}_{4} \mathrm{X}}+\mathrm{k}_{5} \mathrm{X}-\mathrm{k}_{6} \mathrm{X}^{2}+\mathrm{D}_{\mathrm{x}} \frac{\partial^{2} \mathrm{X}}{\partial \mathrm{r}^{2}} \\
& \frac{\partial \mathrm{Y}}{\partial \mathrm{t}}=\mathrm{k}_{7} \mathrm{X}-\mathrm{k}_{8} \mathrm{Y}+\mathrm{D}_{\mathrm{y}} \frac{\partial^{2} \mathrm{Y}}{\partial \mathrm{r}^{2}}
\end{aligned}
$$

Using the same constants that in $3 \mathrm{~B}$, the system is

$$
\begin{aligned}
& \frac{\partial X}{\partial t}=\frac{Y\left(k_{1}-X\right)}{1+X}+X-8.375 \cdot 10^{-6} X^{2}+D_{x} \frac{\partial^{2} X}{\partial r^{2}} \\
& \frac{\partial Y}{\partial t}=k_{7} X-k_{8} Y+D_{y} \frac{\partial^{2} Y}{\partial r^{2}}
\end{aligned}
$$

with the following secular matrix

$$
M_{n}=\left(\begin{array}{lc}
0.9877-D_{x} n^{2} & -0.9959 \\
\varepsilon & -\varepsilon-D_{y} \cdot n^{2}
\end{array}\right)
$$

whose trace is,

$$
\mathrm{T}_{\mathrm{n}}=0.9877-\varepsilon-\left(\mathrm{D}_{\mathrm{x}}+\mathrm{D}_{\mathrm{y}}\right) \cdot \mathrm{n}^{2}
$$

and the determinant,

$$
\operatorname{Det}_{n}=8,176 \cdot 10^{-3} \varepsilon-n^{2}\left(0,9877 D_{y}-\varepsilon D_{x}\right)+D_{x} D_{y} n^{4}
$$

When Det $_{0}>0$, the conditions 0.9877. $\mathrm{D}_{\mathrm{y}}>\varepsilon \cdot \mathrm{D}_{\mathrm{x}}$, and (17) if $\varepsilon=1$ (that means $\mathrm{T}_{0}<0$ ), $\mathrm{D}_{\mathrm{x}}=1, \mathrm{D}_{\mathrm{y}}=2$, can be fulfilled; for example, the value $\mathrm{p}=0.2$ satisfies the conditions for $\operatorname{Det}_{\mathrm{n}}<0$. For that value, the real part of $\omega_{n}$ is $0.2837 / 2$, higher than the part corresponding to $n=0$, that would be $\mathrm{T}_{0} / 2<0$ ( since $\Delta_{0}<0$ ). The homogeneous steady state is a stable focus.

\section{Conclusion}

Except for the polymerisation $\{1,2\}$, the rest of the polymerisations types considered in this paper can fit, at least, to one and frequently to some of the three mentioned oscillators. Supercritical bifurcation defbpf, with limit cycle apparition in absence of diffusion, is possible in all the considered models. Moreover, in all cases, it is possible to get an unstable homogeneous steady state of diffusion, and a homogeneous steady state (stable in diffusion presence) can be destabilized by diffusion. By the moment, it is difficult to predict the scientific [2530] or technological applications that could have the theoretical development made in this paper.

\section{References}

1. Prigogine I, Balescu R (1955) Bull Ci Sci Acad Roy Beig 41: 912.

2. Belousov BP (1959) Sb Ref Radiat Med 147: 145

3. Zhabotinsky AM (1964) Dokl Akad Nauk USSR 157: 392.

4. Bronson R (2008) Ecuaciones diferenciales, McGraw-Hill, México.

5. Fitzgibbon WE (1984) Partial differential equations and dynamical systems. Pitman, London.

6. Thom R (1983) Mathematical models of morphogenesis. Ellis Horwood Ltd. Chichester.

7. Katime I, Pérez-Ortíz JA, Mendizábal E (2011) Simple models of oscillating polymerizations: Dimeric form autocatalysis. Chem Eng Sci 66: 2261-2265.

8. Katime I, Pérez-Ortiz JA, Mendizábal E, Zuluaga F (2009) Harmonic oscillations in a polymerization. Intern J Chem Kin 41: 507-511.

9. Nicolis G, Portnow J (1973) Chemical oscillations. Chem Rev 73: 365-384

10. Balslev I, Degn H (1974) Unified theory of temporal and spatial instabilities. Faraday Symp Chem Soc 9: 233-240.

11. Katime I, Pérez-Ortíz JA, Zuluaga F, Mendizábal E (2010) Minimum models of damped and limit cycle oscillations in a polymerization. Chem Eng Sci 65: 6292-6295.

12. Uppal A, Ray WH, Poore AB (1974) On the dynamic behavior of continuous stirred tank reactors. Chem Eng Sci 29: 967-985.

13. Poincaré $H$ (1885) On the equilibrium of a mass of fluid given a rotational movement. Acta Math 7: 259 
Citation: Katime I, Pérez-Ortiz JA, Mendizábal E (2015) Chemical Oscillations and Spatial Structures in Polymerisation Reactions. Chem Sci J 6: 108. doi:10.4172/2150-3494.1000108

Page 6 of 6

14. Katime I, Pérez-Ortiz JA, Zuluaga F Mendizábal E (2008) Polybrusselator-type models. Int J Chem Kin 40: 617-623.

15. Katime I, Pérez-Ortiz JA, Morales J, Mendizábal E (2014) Models for Oscillating Polymerization: Activation by Product in a System with Flow. Int J Chem Kin 46: 405-417.

16. Rossler OE (1974) Faraday Symp Chem Soc 9: 87

17. Rössler OE (1972) A principle for chemical multivibration. J Theor Biol 36: 413-417.

18. Gray BF, Aarons LJ (1974) Small parasitic parameters and chemical oscillations. Faraday Symp Chem Soc 9: 129.

19. Edelstein BB (1970) Biochemical model with multiple steady states and hysteresis. J Theor Biol 29: 57-62.

20. Edelstein BB (1970) Instabilities associated with dissipative structure. J Theor Biol 26: 227-241.

21. Tyson JJ, Light JC (1973) Properties of two-component bimolecular and trimolecular chemical reaction systems. J Chem Phys 59: 4164.

22. Field RJ, Noyes RM (1974) Oscillations in chemical systems. IV. Limit cycle behavior in a model of a real chemical reaction. J Chem Phys 60: 1877.
23. Tyson JJ (1973) Some further studies of nonlinear oscillations in chemical systems. J Chem Phys 58: 3919.

24. Field RJ, Noyes RM (1974) A model illustrating amplification of perturbations in an excitable médium. Faraday Symp Chem Soc 9: 21-27.

25. Katime I, Pérez JA, Terrón A (1984) Introducción a la termodinámica de procesos irreversibles. Reacciones oscilantes. Servicio Editorial de la Universidad del País Vasco, Bilbao.

26. Lefever R (1974) Faraday Symp Chem Soc 9: 160.

27. Heinrichs M, Schneider FW (1981) Relaxation kinetics of steady states in the continuous flow stirred tank reactor. Response to small and large perturbations: critical slowing down. J Chem Phys 85: 2112-2116.

28. Kanamaru T (2007) Van der Pol oscillator. Scholarpedia 2: 2202.

29. Tyson JJ (1975) Classification of instabilities in chemical reaction systems. J Chem Phys 62: 1010.

30. Epstein IR, Pojman JA (1999) Overview: Nonlinear dynamics related to polymeric systems. Chaos 9: 255-259. 